\title{
Novel human pathological mutations
}

Published online: 5 March 2009

(C) Springer-Verlag 2009

Erratum to: Hum Genet (2008) 124:293-324

DOI 10.1007/s00439-008-0551-3

In Human Gene Mutation article unfortunately at page 320, under the heading "Gene symbol: SH3TC2", one of the author name was repeated twice in the author group of online published article. Author group should read as 'Dolores Martínez-Rubio, José M. Millán, Francesc Palau, Carmen Espinós'. 